\title{
Die elektronische Lohnsteuerkarte kommt
}

- Der Übergang vom papiergebundenen Verfahren zum neuen elektronischen Verfahren ELStAM (Elektronische Lohnsteuer Abzugsmerkmale) ist nunmehr für das Jahr 2013 vorgesehen. Die Einführung wurde bisher mehrfach verschoben und wird auch jetzt nur schrittweise vollzogen. Dadurch soll allen Beteiligten ein reibungsloser Übergang in das neue Verfahren ermöglicht werden.

Die papiergebundene Lohnsteuerkarte 2010 behält bis zur erstmaligen Anwendung der elektronischen Lohnsteuerabzugsmerkmale im Jahr 2013 weiter ihre Gültigkeit. Der Arbeitgeber muss daher die Lohnsteuerkarte des Jahres 2010 bis zur

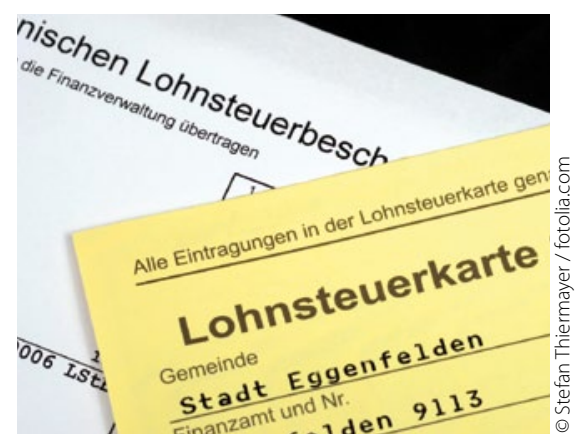

Alte Lohnsteuerkarte: bald Geschichte.

Einführung des elektronischen Verfahrens aufbewahren. Erst nach Einführung des elektronischen Verfahrens darf die Lohnsteuerkarte vernichtet werden.

\section{BSG entscheidet: Niederlassung als "Juristische Person" nur im MVZ}

- Nach einem Urteil des Bundessozialgerichts (BSG) vom 15. August 2012 darf ein Arzt/eine Ärztin nach gegenwärtigem Recht nicht als juristische Person (zum Beispiel als $\mathrm{GmbH}$ ) für die vertragsärztliche Versorgung zugelassen werden. Hintergrund der Klage war eine durch einen Psychotherapeuten angestrebte Übertragung und Fortführung der Praxis in der Rechtsform einer Limited (Ltd.), also einer Kapitalgesellschaft nach englischem Recht, wie sie seit geraumer Zeit auch in Deutschland zulässig ist.

Abgesehen von der Sondersituation bei Medizinischen Versorgungszentren (MVZ) kann jedoch nach Auffassung der Richter nur eine natürliche Person zur vertragsärztlichen Versorgung zugelassen werden, da $\S 95$ SGB V personenbezogen ausgestaltet ist. Die natürliche Person kann von der ihr erteilten Zulassung auch nicht in Form einer Kapitalgesellschaft Gebrauch machen. Diese
Rechtslage ist nach Auffassung des BSG auch verfassungsrechtlich nicht zu beanstanden, denn im Interesse der Sicherung der Versorgungsqualität und der wirtschaftlichen Verantwortlichkeit des behandelnden Arztes darf der Gesetzgeber den Zulassungsstatus den natürlichen Personen vorbehalten. Dies verletzt nach Auffassung des BSG im Hinblick auf die MVZ auch nicht das Gleichbehandlungsgebot (Bundessozialgericht, Urteil vom 15. August 2012, AZ B 6 KA 47/11).

\section{MMW Kommentar}

Damit ist geklärt, dass sich nur natürliche Personen, solange sich nichts grundsätzlich rechtlich ändert, als Vertragsärztinnen/ Vertragsärzte niederlassen können. Lediglich die Gründung eines MVZ als juristische Person ist zulässig, wobei die medizinische Verantwortung der Ärztin/des Arztes in einer solchen Einrichtung nicht tangiert wird.

\section{MMW Kommentar}

Arbeitgeber, die das elektronische Verfahren nutzen, können die von der Finanzverwaltung bereitgestellten elektronischen Lohnsteuer-Abzugsmerkmale ihrer Arbeitnehmer, wie z. B. die Steuerklasse und Freibeträge, abrufen. Dazu benötigen sie lediglich dessen Identifikationsnummer sowie das Geburtsdatum. Der Abruf der Daten durch den Arbeitgeber ist freiwillig ab 1.11.2012 möglich. Ab 1.1.2013 besteht zwar für jeden Arbeitgeber die Pflicht, das Verfahren zu nutzen, die Finanzverwaltung gewährt jedoch eine Kulanzfrist bis zum 31.12.2013.

In der Vergangenheit übernahm das Finanzamt die Freibeträge aus den Vorjahren automatisch. Die auf der Lohnsteuerkarte 2010/Ersatzbescheinigung 2011 bzw. 2012 für den Übergangszeitraum eingetragenen Freibeträge und antragsgebundenen Kinderzähler (z. B. für Kinder, die zu Beginn des Kalenderjahres 2012 oder zu Beginn des Kalenderjahres 2013 das 18. Lebensjahr vollendet haben oder Pflegekinder) gelten im elektronischen Abrufverfahren grundsätzlich nicht weiter. Folglich sind diese für das Kalenderjahr 2013 beim zuständigen Finanzamt neu zu beantragen. Diese Anträge können und sollten jetzt schon gestellt werden, um steuerliche Nachteile zu vermeiden. Sie sind aber - spätestens bis zum 30.11.2013 - auf amtlichen Vordrucken zu stellen. Arbeitgeber sollten ihre Arbeitnehmer darüber persönlich oder über einen Aushang informieren! 